\title{
Determining The Time Of Death By The Development Of Flies In Wistar Rat In The Coastal Area In Sabang City
}

\author{
Zulfia Retnanti Marissa, Alfred C Satyo, Agustinus Sitepu \\ Magister of Clinical Medicine Student in Medical Faculty of North Sumatera University \\ DOI: 10.29322/IJSRP.11.11.2021.p11946 \\ http://dx.doi.org/10.29322/IJSRP.11.11.2021.p11946
}

\begin{abstract}
Background: The time of death can be determined by identifying the changes in the corpse such as by identifying the flies found in the corpse. In the corpse, fly is an animal that will perch on it, sometimes just a few minutes after death. Fly is one important species in forensic medicine. In corpse, large number of flies can be found which makes it possible to use flies to determine the time of death. The interval of which the flies lay eggs to the developmental phase of the flies can be used in determining the time of death.
\end{abstract}

Methods: This is an observational study with cohort and prospective design in which the development of flies in wistar rat will be examined and observed from the fly's egg to the final phase of the fly's development. This study was performed in Sabang city, in Aceh Province. Sabang city is the capital of Weh island, which is an island surrounded by coastal areas. This study was conducted from March to May in 2021. The population in this study were wistar rats. The samples in this study were wistar rats which has been conditioned for a week. The wistar rats was caged and then placed near the coast. There were 5 wistar rats of 2-3 months old with an average weight of 150-200 grams. The rat's neck was dislocated and then an incision of $1 \mathrm{~cm}$ length was performed in the right upper abdomen of the rats and changes will be observed, the developments of the fly's egg to the pupa and the numbers of the fly on the sample was identified.

Results: The development of fly's life cycle in the coastal area of Sabang city. The samples of this study were 5 wistar rats wight from 150-200 grams whihch has been conditioned and adapted for one week. The rats were dislocated in the neck, and then caged. The mouse corpse was observed daily at the same hour. The observation of the larvae development and larva stage started from the first-time larvae was noticed in the wistar rat corpse, 5 largest larvae from each sample was taken, larvae instar I with a mean size of $3.2 \mathrm{~mm}$ was found. In the estimated time of death of two to three days, larvae instar II with a mean size of $6.3 \mathrm{~mm}$ was found. In the estimated time of death of four to seven days, larvae instar III with a mean size of $9.3 \mathrm{~mm}-17.8 \mathrm{~mm}$ was found. In the estimated time of death of eight to nine days, an inactive brownish white prepupa with a mean size of $10-13 \mathrm{~mm}$ was found. In the estimated time of death of ten to thirteen days, pupa with a mean size of $9 \mathrm{~mm}-10 \mathrm{~mm}$ was found. Fly was found after thirteen to fourteen days.

Conclusion: The life cycle of larva in the coastal area of Sabang city was around 13 days in which there were 1 day each for instar
I and instar II phase, 3 days for instar III, 2 days of prepupa and 6 days of pupa to adult fly. The maximum length of the larva observed was $17.8 \mathrm{~mm}$ during the $4^{\text {th }}$ day. the larvae found was from the sarchophagidae and calliphoridae family with the genus Sarcophaga sp. And Phormia sp.

Index Terms- Identification of changes, time of death, larvae's length

\section{BACKGROUND}

$\mathrm{T}$ he rate of criminality was estimated to be increasing, either nationally or globally. The recorded global criminal rate of murder was increasing from 362,000 cases in 1990 to 464,000 cases in 2017. This number was predicted to raise until 2030. Meanwhile, the number of criminal cases in Indonesia from 20162018 was 357,197 cases in 2016, 326,652 cases in 2017 and 294,281 cases in 2018. Similar to the decreasing trend of national criminal cases, the number of criminal cases in Aceh Province in 2016-2018 also decreases which were 129 cases in 2017, 113 cases in 2018. The number of criminal cases was used to determine the crime vulnerability in a specific time in a certain area.

Discovery of dead body which was reported several times was crime victims, even though not all the cases can be categorized as crime victim. To determine the actual cause of death, body identification of the corpse must be performed.

Dead body identification consists of external examination and internal examination. External examination was performed by a forensic entomologist to examine insects. From this examination, the cause, mechanism, and the time of death be determined. Dead body identification was performed by a forensic doctor. The result of these processes was called visum et repertum. Dead body identification consists of external examination and internal examination. External examination was performed by a forensic entomologist to examine insects. From this examination, the cause, mechanism, and the time of death be determined.

The time of death can be determined by identifying the changes in the corpse, such as identifying flies found in the corpse. Fly was the first living creature that will perch on the corpse, sometimes only a few minutes after death. Fly was also the most important species in forensic medicine. Also, flies were found in large numbers which makes it possible to use it to predict the time of death. The period in which the fly laid eggs until the developmental stages can be used to estimate the time of death.

The species of the fly was identified by measuring the larvae's length. It was estimated that after 36-48 hours of death, 
the larvae will be visible which marked the decomposition process. This method has been used all over the world, such as the report of the study by Wang et al (2019), Metcalf (2019), Laksmita (2013), Panusunan (2020), Bonacci et al (2017), Badenhorst and Villet (2018), Fernando (2018), and Pai (2007).

Factors that affect larvae's growth was also an indirect factor that affect the time of death, such as the availability of free air, the temperature of the environment, the corpse temperature, and the location of the dead body, inside or outside a building. Another determining factors was the geographical location which may affect the size of the larvae and the type of the larvae. Identifying the changes of fly also useful in determining drugs that was contained in the dead body. Not only larvae, identification of the adult fly's age was also used to determine the time of death.

Sabang is one of the cities in Aceh Province and is an archipelago surrounded by coastal area, Sabang is the Westernmost region of Indonesia.

Geographically, Sabang city was in the coordinate of $05^{\circ} 46^{\prime} 28^{\prime \prime}$ ' $-05^{\circ} 54^{\prime} 28^{\prime \prime}$ "North latitude and $95^{\circ} 13^{\prime} 02^{\prime \prime}=95^{\circ} 22^{\prime} 36^{\prime \prime}$ East longitude. The northern border of Sabang city was Malacca strait, on the southern border, Bay of Bengal and on the Western border of Sabang city was Indonesia Sea with its region area of $153 \mathrm{~km}$. The population in 2019 was 34,333. There was a possibility that this city might be free of criminality. The body identification process was commonly performed, however there has not been any publications in prior to entomology body identification, especially which uses fly as an indicator to determine the time of death.

\section{METHOD}

This is an observational study with cohort or prospective design in which the development of fly in wistar rats was observed from egg to the final phase of the fly's development.

This study was conducted in one of the cities in Aceh Province, which is Sabang city. Sabang city is the capital of Weh island which is an archipelago surrounded by coastal areas. This study was conducted from March to May 2021.

The population of this study were wistar rats. The samples of this study were wistar rats which has been conditioned for a week. These wistar rats will be caged and put in coastal area. There were 5 wistar rats.

The samples in this study will be filtered through several criteria of inclusion and exclusion. The criteria of inclusion in this study were:

a) Wistar rats which has been conditioned for a week

b) Wistar rats aged from 2-3 months

c) Wistar rats weighed from 150-200 grams

d) Healthy wistar rats

The criteria of exclusion in this study were:

a) The rats died before the study was performed

b) The rats become sick during conditioning period

The steps of this study were as follows:

1. Five wistar rats were caged.

2. The rats were conditioned and for a week, these rats were fed regularly.

3. The rats were killed by dislocating its neck and then a 1 $\mathrm{cm}$ incision was made in the right abdomen, and then stored in a containment cage.
4. Wait until the fly perch on the corpse and lays egg. The observation started in this step.

5. If a change was visible in the samples, larvae was measured. The measurement was performed by submerging the larvae into hot water and $70 \%$ alcohol to kill the larvae and then measured using millimeter paper and then recorded.

6. The larvae were identified using microscope. The identification process was performed in the laboratories owned by Faculty of Science and Mathematics in the University of North Sumatera, Medan.

\section{RESULTS AND DISCUSSION}

Characteristic of the Samples

During Day-0 of observation, several hours after the rats has been dislocated, flies were seen perching on the rat's corpse and were ready to lay eggs. In this time also, larva instar I was found, which was potentially a larva from Sarcophaga genus, in which this genus immediately produces larva instar I.

During Day-1 of observation, larva instar II was found, with a mean length of $6.3 \mathrm{~mm}$, the larvae were with hand were active. The rat's corpse was bloating in their abdomen due to the activity of the microbial agents inside the rat's corpse.

During day-2 of observation, larva instar III was found, in which these larvae were very active in feeding. The observed larvae instar III were having a mean length of $9.3 \mathrm{~mm}$, and were milky white. Fluid was leaking from the rat's corpse. The instar III phase occurred until day-4 in which it was known that instar phase III is the phase that occurred the longest, compared to the other phase. The mean length of the larvae during third of observation was $13.8 \mathrm{~mm}$ while on the fourth day was $17.8 \mathrm{~mm}$. a brownish white larva was visible and was ready to transform into prepupa.

Prepupa phase was visible during day 5 , in which the larva was becoming less active and moving to drier place away from the corpse. The prepupa phase was occurring in two days until day 6.

In observation day 7, pupa was visible. Brown and inactive pupa was visible. The observation was performed on the next day until a fly larva from the pupa was visible until it transformed into an adult fly.

In observation day 13 the pupa has been transformed into an adult fly; the fly was then identified to determine its type.

Based on table 4.1 it was shown that the development of larva in the rat's corpse around the coastal area of Sabang city takes up to 13 days until it transformed into an adult fly. Respectively, instar I and instar II phase each took 1 day, instar III phase took 3 days, prepupa phase took 2 days and then 6 days for the pupa to transform into an adult fly. The length of the larva is correlated to its developmental phase. 
Table 4.1 Examination of larva development

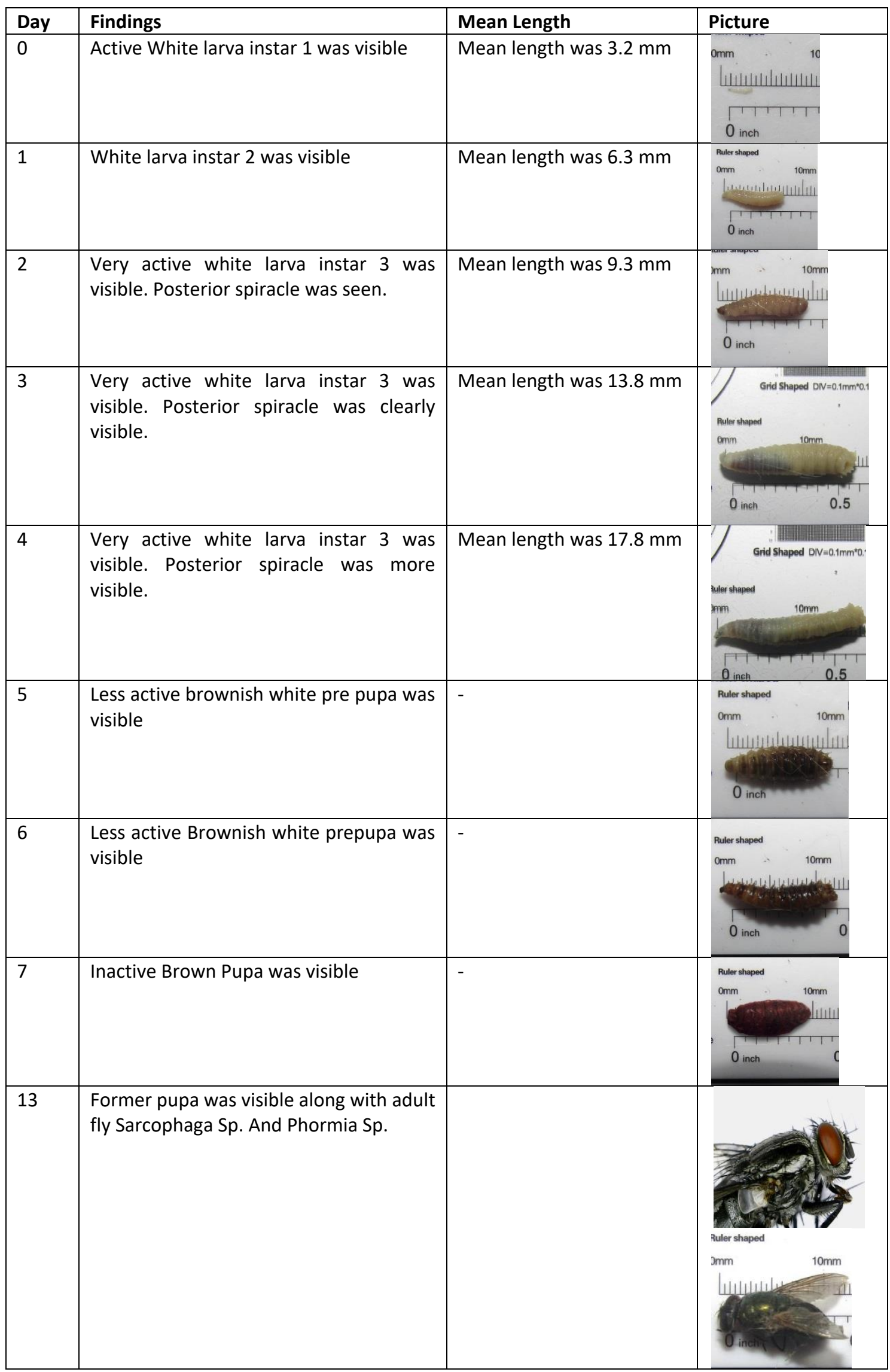


The life cycle of the fly in this study was fast, this was probably due to the higher temperature in the coastal area which will accelerate the decomposition process of the corpse. Direct sunlight exposure also making the corpse dry faster which prevent the repeated colonization process.

Based on table $\mathbf{4 . 3}$ above, we can see that the minimal length of the larva was found in day 0 which was $3.0 \mathrm{~mm}$, while the highest length of the larva was observed on day- 4 which was $18.6 \mathrm{~mm}$.

Table 4.3 Observation of larva length

\begin{tabular}{|c|c|c|c|c|c|c|}
\hline \multirow{2}{*}{$\begin{array}{l}\mathrm{Da} \\
\mathrm{y}\end{array}$} & \multicolumn{5}{|c|}{ Larvae's length (mm) } & \multirow{2}{*}{$\begin{array}{l}\text { Mea } \\
\text { n }\end{array}$} \\
\hline & $\begin{array}{l}\text { Repeat } \\
\text { ed n1 }\end{array}$ & $\begin{array}{l}\text { Repeat } \\
\text { ed } n 2\end{array}$ & $\begin{array}{l}\text { Repeat } \\
\text { ed n3 }\end{array}$ & $\begin{array}{l}\text { Repeat } \\
\text { ed n4 }\end{array}$ & $\begin{array}{l}\text { Repeat } \\
\text { ed n5 }\end{array}$ & \\
\hline $\mathrm{HO}$ & 3.0 & 3.0 & 3.0 & 3.0 & 4.0 & 3.2 \\
\hline $\mathrm{H} 1$ & 6.8 & 6.6 & 6.5 & 6.6 & 5.9 & $\begin{array}{l}6.37 \\
5\end{array}$ \\
\hline $\mathrm{H} 2$ & 9.5 & 8.9 & 9 & 9.7 & 9.8 & 9.38 \\
\hline $\mathrm{H} 3$ & 13 & 14.6 & 13.6 & 13.6 & 14.5 & $\begin{array}{l}13.8 \\
6 \\
\end{array}$ \\
\hline $\mathrm{H} 4$ & 18.6 & 17.1 & 17.2 & 18.1 & 18.3 & $\begin{array}{l}17.8 \\
6 \\
\end{array}$ \\
\hline H5 & \multicolumn{6}{|l|}{ Prepupa } \\
\hline $\mathrm{H} 6$ & \multicolumn{6}{|l|}{ Prepupa } \\
\hline $\mathrm{H} 7$ & \multicolumn{6}{|l|}{ Pupa } \\
\hline $\mathrm{H} 8$ & \multicolumn{6}{|c|}{ Imago/adult Fly } \\
\hline
\end{tabular}

The identification of the fly type was performed under microscope by observing the morphology of the posterior spiracle during the larva instar phase (table 4.4). Based on the identification, two spesies of larva was found which was larva from Sarcophagidae family under the genus Sarcophaga sp. And Calliphoridae family under the genus Phormia sp.

Table 4.4 The type of larva found

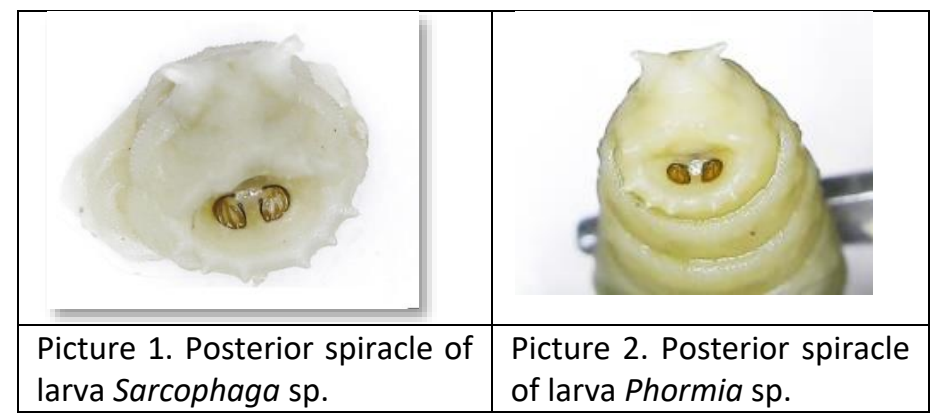

According to Gennard (2007), to determine the time of death, the oldest colony of insects must be determined, and its life cycle must be observed. According to prior study performed by Laksmita et al (2015) on the genus Sarcophaga showed that the time of death was estimated to be around 14-24 days, if pupa was found, the estimated time of death was around 6-18 days, if larva instar 3 was found, the estimated time of death was around 3-7 days, if larva instar 2 was found, the estimated time of death was during day 0 of observation, several hours after the rats were dislocated, fly was visible on the corpse, ready to lays egg. At the same time also, larva instar 1 was found which was possibly from the Sarcophaga genus, in which this genus of fly immediately produces larva instar I.

According to Rusidi and Yulianti (2019), the posterior spiracle in the Calliphoridae family had a protection structure (peritreme) which was connected, and protrude to the proximal site, while on Sarcophagidae family, the spiracle protector (peritreme) was not connected, and no botton on its base.

According to Isfandiari (2009), Calliophoridae family (Blow flies) will be visible after a few minutes and will form the first colony on the corpse. The female flies will lay a huge number of eggs in the nostrils, mouth, and open wound while Sarcophagidae family (Flesh flies) showed an interest to almost all kinds of corpse, either high or low temperature. This family of flies was visible on the corpse just after the blowflies was visible. Sarcophaga was ovoviviparous in which this fly immediately lays a larva instar 1 on the corpse.

If we look at a prior study by dr. Panusunan Simatupang, M.Ked (For)., Sp.F who had performed a study in Toba lake which was a highland area, there was a difference in the duration of time needed for the larva to become a fly in which it took a longer time of 14 days compared to the development of fly in coastal areas which was 13 days, even if this difference was minor, this was affected by the temperature and humidity of the area, and the type of the fly found in the Toba area was Sarcophaga Sp, Chrysoma sp, and Chrysoma Megachepala, whihle in the coastal area of Sabang city was Sarcophagidae and calliporidae family with Sarcophaga sp. And Phormia sp. Genus.

In the study conducted by dr. M. Fernando Manik, SH., M.Kes., M.Ked (For)., Sp.F which studied on the fly life cycle in Medan city.

\section{CONCLUSION}

1) The life cycle of larva in the coastal area in Sabang city was 13 days in which it was 1 day each for instar I and II phase, 3 days for instar III, 2 days for prepupa and 6 days for the pupa to be transformed into adult fly.

2) The maximum length of the larva was $18.6 \mathrm{~mm}$ in day4.

3) The type of larva found was from sarcophagidae and calliphoridae family and Sarcophaga sp. And Phormia sp.

\section{AUTHORS}

First Author - Zulfia Retnanti Marissa, Medicine Student in Medical Faculty of North Sumatera University, Email:

Fia.Marissa22@gmail.com

Second Author - Alfred C Satyo, Marissa, Medicine Student in Medical Faculty of North Sumatera University

Third Author - Agustinus Sitepu, Marissa, Medicine Student in Medical Faculty of North Sumatera University 
